\title{
Socio-demographic Factors, Dental Status, Oral Health Knowledge \& Attitude, and Health-related Behaviors in Dental Visits Among 12-year-old Shenzhen Adolescents: a Multilevel Analysis
}

\author{
Jinfeng He \\ Sichuan University \\ Bo Yuan \\ Longhua People' s Hospital Affiliated to Southern Medical University \\ Shanyu Zhou \\ Longhua People' s Hospital Affiliated to Southern Medical University \\ Shuyuan Peng \\ Longhua People' s Hospital Affiliated to Southern Medical University \\ YeXu \\ Sichuan University \\ He Cai \\ Sichuan University \\ Li Cheng ( $\nabla$ dentistcl@foxmail.com ) \\ Sichuan University \\ Yuehua You \\ Longhua People' s Hospital Affiliated to Southern Medical University \\ $\mathrm{TaOHu}$ \\ Sichuan University
}

\section{Research Article}

Keywords: Adolescents, Cross-sectional study, Dental visits, Shenzhen, Oral health

Posted Date: October 26th, 2021

DOI: https://doi.org/10.21203/rs.3.rs-985480/v1

License: (c) (7) This work is licensed under a Creative Commons Attribution 4.0 International License. Read Full License

Version of Record: A version of this preprint was published at BMC Oral Health on March 31st, 2022. See the published version at https://doi.org/10.1186/s12903-022-02110-8. 


\section{Abstract}

Background: Dental visits can provide education, prevention and treatment measures for teenagers, and help to form correct oral health knowledge and attitude. The purpose of this study was to evaluate the effects of socio-demographic factors, dental status, oral health literacy, and health-related behaviors on dental visits in early 12-year-old adolescents.

Methods: 953 subjects aged 12 in Longhua District of Shenzhen were investigated. The questionnaire and clinical examination were applied in schools, and two-level logistic regression models were constructed to interpret the effect of individual and contextual factors on Shenzhen adolescents' dental visits.

Results: A total of $27.6 \%$ of the participants had not been to a dentist. After the multiple factors binary logistic regression analysis, it confirmed that the following variables: Shenzhen hukou (OR $=2.133,95 \% \mathrm{Cl}$ : 1.429-3.185)】 moderate caries ( $\mathrm{OR}=1.404,95 \% \mathrm{Cl}: 1.022-1.928)$ and severe caries $(\mathrm{OR}=2.546,95 \% \mathrm{Cl}: 1.461-4.437) \llbracket$ Angle Class II malocclusion( $\mathrm{OR}=1.703,95 \% \mathrm{Cl}: 1.134-2.556)$, sometimes or never toothbrushing (OR $=2.985,95 \% \mathrm{Cl}: 1.491-5.975)$, Dental floss usage ( $\mathrm{OR}=1.829,95 \% \mathrm{Cl}: 1.250-2.677)$, having had a toothache within the last 12 months (OR $=1.469,95 \% \mathrm{Cl}$ : 1.0861.986), high Knowledge attitude level $(\mathrm{OR}=1.570,95 \% \mathrm{Cl}: 1.106-2.229)$, moderate Knowledge attitude level $(\mathrm{OR}=1.534,95 \%$ Cl: 1.073-2.193), were associated factors for dental visit experience.

Conclusions: The dental visits of 12-year-old children in Longhua District of Shenzhen is affected by multi-dimensional factors. It is suggested that oral health education should be strengthened, good oral hygiene habits should be cultivated, and the needs and utilization of oral health services for non-Shenzhen adolescents should be paid attention to, so as to effectively improve the overall oral health level of adolescents.

\section{Introduction}

Dental caries is one of the most common oral diseases and the most important global oral health burdens with high prevalence around the world [1]. Dental caries is not only a childhood disease, but also can continue into adulthood [2], where health inequality still exists [3]. Adolescence is a transitional period from childhood to adulthood, an important milestone of physical, psychological and social transformation, it is also the key to the formation of oral health concepts and habits. In the worldwide, the prevalence of dental caries in this stage ranged from $54-78 \%[1,4]$.

The availability and accessibility of oral health services are very important for the control of dental caries. Dental visits can provide education, prevention and treatment measures for teenagers, and help to form correct oral health knowledge and attitude. However, in developed countries, the rate of dental visits is $44 \%$, and in developing countries, $18 \%-38.3 \%$ of 12 year-old children have never seen a dentist or have not seen their teeth regularly [1]. The related factors affecting the dental visits of adolescents are complex, which need more attention.

Shenzhen, as a city with rapid economic growth, is also a city of immigrants. The number of children of migrant workers is huge, especially the Longhua District, which has a certain representativeness. There are many conditions for Shenzhen hukou to be included. Generally speaking, it represents a higher cultural level and better economic conditions. It has a certain degree of screening function for the resident population. In Shenzhen, Hukou restricts the eligibility to buy a house and children's schooling. The unfair distribution of resources brought by social development has always been the focus of the policymakers' efforts,Economic and sociological theories pay more and more attention to the coordination of social development and economic development; To achieve the equalization of public services and inclusive development, in the final analysis, is also to achieve coordinated economic and social development, so that the fruits of economic growth can be fully shared by the people. To explore the dental treatment situation among different populations in Shenzhen will help to provide the government with the basis for oral health decision-making, eliminate the differences in oral health caused by the gap between the rich and the poor, and provide qualified labor force. 
At present, the research on dental visits mainly focuses on sociodemographic factors, clinical factors and oral health literacy. etc. Sociodemographic factors are considered to influence the use of dental services through personal health behaviors. Family environment can affect the formation of oral health habits of children and adolescents, which was related to oral health behavior, eating habits and dental caries $[5,6]$. Studies have reported the relationship between dental caries, toothache and the use of dental services by adolescents. We found an association between high oral health literacy and recent dental service use in adults, a higher level of occupational health helps to reduce inequalities in access to health care and dental information, which helps to visit dentists [7].

Oral health-related quality of life (OHRQoL) is an important indicator that can comprehensively reflect the impact of an individual's oral health problems or diseases on their physiological, psychological and social functions. Compared with objective indicators of oral examination, OHRQoL is a subjective indicator, which is an important part of patients' outcome report, including self-evaluation of oral health status, functional health, mental health, health service expectation and satisfaction and self-feeling [8]. In recent years, OHRQoL has been widely used in oral health survey and clinical research [9].

However, the impact of these factors on dental visits has not been fully explored in Chinese youth groups, especially in Shenzhen, one of the most characteristic cities. Exploring the relationships between dental visits and possible contributing factors may be beneficial for developing targeted interventions and healthcare policies. Therefore, the purpose of this study was to evaluate the effects of oral health literacy, sociodemographic, clinical and family characteristics on dental visits in early 12-year-old adolescents.

\section{Methods}

\section{Study design}

An analytical, cross-sectional study was conducted with 12-year-old students enrolled in public and private schools in the city of Shenzhen, China. Data collection was performed from 11/23/2020 to 11/27/2020. Ethics approval was obtained from Medical Ethics Committee of Longhua People' s Hospital Affiliated to Southern Medical University (Approval No. KY20201104).

\section{Survey sampling}

Two-stage probabilistic cluster sampling was performed to select participants who were representative of the Longhua District of Shenzhen population. In the first stage, the number of private and public schools was selected. In the second stage, specific schools were selected, and the probability proportional to size sampling (PPS) was used for each school. The number of students included in the study was representative and proportional to the number of Shenzhen hukou and nonShenzhen hukou students in the population of each district.

A letter of invitation and informed consent form were sent to the guardian of potential participants firstly, emphasizing that the participation was voluntary. Participants and their statutory guardians were required to sign informed consent forms. Adolescents with serious physical or psychological illness or disadvantages, who were unable or unwilling complete the examination and questionnaire, were excluded. Ultimately, a random sample of students completed the survey; this number was greater than the expected participants calculated by the formula:

$$
N=\operatorname{def} f^{*}\left(\frac{\mathrm{Z}_{\alpha / 2}}{\delta}\right)^{2} \Pi(1-\Pi)
$$

in which the allowable error $\delta=0.05$ and $a=0.05$ was adopted. $\pi$ adopted the prevalence of gingival bleeding in people at aged 12 years from the Fourth National Oral Health Survey in China $p=58.4 \%$ [10]. A design effect of 2 was considered to correct for the sampling method, resulting in a sample of 747 adolescents. Then, $20 \%$ was added to compensate for 
expected missing data. The final sample was 934 adolescents. According to the class sampling survey of 100 students, a total of 10 schools needed to be selected.

\section{Quality control}

Quality control was conducted as following: three licensed dentists, who had worked for more than 2 years and cooperated with three recorders, were trained by a standard examiner (the fourth examiner) before beginning this survey. The Cohen's Kappa statistic was used to assess the inter-examiner variability of dental caries in adolescents and the final Kappa scores obtained on inter- or intra-examiner variability were $\geq 0.75$. Furthermore, the inter-examiner variability in three regions during the survey were $\geq 0.75$ as well.

\section{Questionnaire}

The questionnaire was distributed to 1000 participants in 12 years old in Shenzhen.

All participants were asked to fill out the self-reported questionnaire, including demographic variables, socioeconomic status, diary habit, oral health behavior, oral health-related knowledge, oral health-related attitude and the impact on oral health-related quality of life. The annual household income was not investigated because students may not be certain about it, and it was a sensitive issue. Therefore, the socio-economic status here was tested by the economic situation of the street where the school is located and the parental educational level [11]. Parental educational level was classified into two levels: $\leq 8 \mathrm{y}$ and $\varangle 8 \mathrm{y}$. Sugar intake level involved the consumption of desserts and candies, carbonated beverage (e.g., cola) and sugary drinks (e.g., sugary tea), which were clarified by five levels: Never, 1-3/month, 1/week, 2-6/week, 1/day, more than $2 /$ day. These five levels were assigned with " Never " = 1, " $1-3 /$ month " = 2, " $1 /$ week " = 3, "2-6/week " = 4, " $1 /$ day " = 5, " More than 2/day " $=6$ points, and then added the scores of 3 items, with the total score ranging from 3 to 18 points. The higher the total score, the more the sugar intake. The total score is divided into three grades according to the tri-sectional quantiles of accuracy. Oral health behavior included the frequency of tooth brushing (more than once a day, once a day, less than once a day, never,divided the participants into sometimes or never/daily), the frequency of dental flossing (daily, weekly, occasionally, never, divided the participants into dental flossing usage /not) and the dental visit experience, as determined from the question 'Did you ever go to the dentist?' and clarified as yes and no. Oral health-related knowledge and attitude were evaluated by twelve questions about the understanding of the cause and prevention of oral diseases, the importance of oral health and the way to promote oral health. We rated each question with a score of 1 for correct answers, a score of 0 for wrong answers or unknown. We calculated the rate of correct answers and divided the participants into low, intermediate and high levels of knowledge and awareness according to the tri-sectional quantiles of accuracy [12]. The modified oral impact on daily performance (OIDP) scale was used to measure oral health-related quality of life (OHRQoL), which was widely used in the Fourth National Oral Health Survey in China. The scale included nine aspects: eating, pronunciation, brushing teeth or gargling, doing housework, going to school, sleeping, grinning, easy to worry and interpersonal communication. The items were simple and easy to understand, which was convenient for teenagers to make clear answers according to their own actual situation. As for the total score of 9 items in the OIDP scale, this study first assigned the options with "serious impact" = 1, "general impact" = 2, "slight impact" = 3, "no impact" = 4 points, and then added the scores of 9 items, with the total score ranging from 9 to 36 points. The lower the total score, the worse the oral health-related quality of life. The total score is divided into two grades. The total score $>27$ is no influence, and the total score $\leq 27$ is influence.

\section{Clinical assessment}

All clinical procedures were conducted in the adolescents' school in the following sequence. Each participant in the selected regions received an oral health examination by a trained licensed dentist according to the criteria issued by the WHO [13]. The portable equipment used consisted of a dental chair, external light source, plane mouth mirrors, air compressor and the community periodontal index probe (WHO/CPI probe) in conjunction with WHO clinical criteria and visual examinations [13]. Gingival bleeding was defined as the presence of gingival bleeding upon gentle probing (BOP) in at least one site [13]. The gingival calculus was explored by using CPI probe. The probe started just distal to the midpoint of the buccal surface and then gently moved into the mesial interproximal area. The same procedure was completed on the palatal surface. Bleeding

Page $4 / 12$ 
sites were scored after the sites of a single quadrant were probed. Each site was scored as no bleeding $=0$ and $b l e e d i n g=1$. A gentle tactile exam was used to locate calculus deposits. Each site was scored as followings: no calculus =0; calculus = 1. Missing (not yet erupted, or extracted) or excludable (dental caries, extensive restorations or orthodontic bands or brackets) were not evaluated [14]. Dental plaque, probing depth, and clinical attachment level were not assessed. No radiographic examination was performed.

After completing the oral examination, all adolescents received an oral evaluation form to take home. This form classified the child's oral health status according to the severity of the oral findings and recommended the timing of their next dental visit $[13,14]$. Those adolescents with calculus would be recommended that they "must visit a dentist as soon as possible".

\section{Statistical analysis}

The data were independently extracted for the statistical analyses by two of the authors (H. C. and R. Z.). The whole information was extracted from the questionnaires and the oral health assessment form. EpiData Version 3.1 (EpiData Association, http:// www.epidata.dk, Epidata Association, Odense, Den- mark) was used for data capture. In order to ensure the consistence and the accuracy of the data, the items were assessed more than 3 times during the input process. Any disagreements or mistakes were assessed further and dealt by the original data in questionnaires.

Descriptive analysis was performed, followed by bivariate and multivariate analyses using logistic regression analysis for complex samples. The dependent variable was dichotomized (yes/no) based on the adolescents' reports of having dental visit experience. Variables with a $P$-value $<0.05 .10$ Variables in the univariate bivariate analysis were incorporated into the multivariate analysis. Variables with a $P$ value $<0.05$ were maintained in the final model. Odds ratios (OR) and $95 \%$ confidence intervals $(\mathrm{Cl})$ were presented in both the bivariate and multivariate analysis. No multicollinearity problems were found among the variables in this study. The statistical procedures were performed in SPSS Statistics for Windows, version 22.0 (IBM Corp., Armonk, NY, USA).

\section{Results}

A total of 1000 subjects aged 12 years were selected for eligibility in this study with an effective response rate of $95.3 \%$. The final sample was composed of 953 12-year-old adolescents, 460 (48.3\%) of whom attended public schools and 492 (51.7\%) attended private schools. The non-response rate was $4.7 \%$. Losses occurred due to successive absences from school on the days scheduled for the dental examinations $(n=21)$ and refusal to participate $(n=26)$. Among the participants, $49.1 \%(n=$ 468 ) of the participants were boys, and $50.9 \%(n=485)$ were girls. A total of $27.6 \%$ of the participants had not been to a dentist within the last 12 months. The details of the total data were showed in Table 1. 
Table 1

Descriptive characteristics of the participants $(N=953)$

\begin{tabular}{|c|c|c|c|}
\hline Variables & & Number & Percent \\
\hline \multirow[t]{2}{*}{ Gender } & male & 468 & $49.1 \%$ \\
\hline & female & 485 & $50.9 \%$ \\
\hline \multirow[t]{2}{*}{ Hukou } & Shenzhen & 227 & $23.8 \%$ \\
\hline & Non-Shenzhen & 726 & $76.2 \%$ \\
\hline \multirow[t]{2}{*}{ Street economy } & good & 564 & $59.2 \%$ \\
\hline & poor & 389 & $40.8 \%$ \\
\hline \multirow[t]{2}{*}{ Father's educational level } & $\leq 8 \mathrm{y}$ & 407 & $42.7 \%$ \\
\hline & $>8 y$ & 546 & $57.3 \%$ \\
\hline \multirow[t]{2}{*}{ Mother's educational level } & $\leq 8 \mathrm{y}$ & 481 & $50.5 \%$ \\
\hline & $>8 y$ & 472 & $49.5 \%$ \\
\hline \multirow[t]{3}{*}{ Caries degree } & zero & 465 & $48.8 \%$ \\
\hline & moderate & 370 & $38.8 \%$ \\
\hline & severe & 118 & $12.4 \%$ \\
\hline \multirow[t]{2}{*}{ Gingival bleeding } & No & 248 & $26.0 \%$ \\
\hline & Yes & 705 & $74.0 \%$ \\
\hline \multirow[t]{2}{*}{ Calculus } & No & 597 & $62.6 \%$ \\
\hline & Yes & 356 & $37.4 \%$ \\
\hline \multirow[t]{2}{*}{ Angle Class II malocclusion } & No & 767 & $80.5 \%$ \\
\hline & Yes & 186 & $19.5 \%$ \\
\hline \multirow[t]{2}{*}{ Angle Class III malocclusion } & No & 730 & $76.6 \%$ \\
\hline & Yes & 223 & $23.4 \%$ \\
\hline \multirow[t]{2}{*}{ anterior deep overjet } & No & 371 & $38.9 \%$ \\
\hline & Yes & 582 & $61.1 \%$ \\
\hline \multirow[t]{2}{*}{ Toothbrushing frequency } & Daily & 915 & $96.0 \%$ \\
\hline & Sometimes or never & 38 & $4.0 \%$ \\
\hline \multirow[t]{2}{*}{ Dental floss usage } & No & 714 & $74.9 \%$ \\
\hline & Yes & 239 & $25.1 \%$ \\
\hline \multirow[t]{3}{*}{ Sugar intake level } & high & 224 & $23.5 \%$ \\
\hline & moderate & 606 & $63.6 \%$ \\
\hline & low & 123 & $12.9 \%$ \\
\hline \multirow[t]{2}{*}{ Toothache within the last 12 months } & No & 468 & $49.1 \%$ \\
\hline & Yes & 485 & $50.9 \%$ \\
\hline
\end{tabular}




\begin{tabular}{|llll|}
\hline Variables & & Number & Percent \\
\hline Dentist visit experience & No & 263 & $27.6 \%$ \\
\cline { 2 - 4 } & Yes & 690 & $72.4 \%$ \\
\hline Knowledge-attitude level & high & 306 & $32.1 \%$ \\
\cline { 2 - 4 } & moderate & 313 & $32.8 \%$ \\
\hline Affect the OHRQoL & low & 334 & $35.0 \%$ \\
& No & 247 & $25.9 \%$ \\
\cline { 2 - 4 } & Slight & 614 & $64.4 \%$ \\
\cline { 2 - 4 } & Yes & 92 & $9.7 \%$ \\
\hline
\end{tabular}

In Table 2, the overall prevalence of dental caries was 51.2\% (52.0\% in Shenzhen hukou and $51.0 \%$ in non-Shenzhen hukou, respectively). The overall mean DMFT caries was 1.31 (1.33 and 1.30 in Shenzhen hukou and non-Shenzhen hukou, respectively). The filling rate was $26.9 \%$, and this value was higher in Shenzhen hukou (44.0\%) than non-Shenzhen hukou (21.4\%). We define active caries as DT $\otimes 0$ to describe the number of existing caries,the results showed that the prevalence of active caries in Shenzhen hukou was $37.5 \%$, which was lower than non-Shenzhen hukou(45.0\%). Then we found that the filling ratio of dental caries was different between Shenzhen hukou and non-Shenzhen hukou, so we were interested in the direct reason of the filling difference, and then led to logistic regression to explore the influencing factors of dental visit.

Table 2

Dental status in Longhua District of Shenzhen

\begin{tabular}{|c|c|c|c|c|c|c|}
\hline & & \multicolumn{2}{|c|}{ DMFT } & \multirow{2}{*}{$\begin{array}{l}\text { Prevalence of dental } \\
\text { caries(\%) }\end{array}$} & \multirow{2}{*}{$\begin{array}{l}\text { Filling } \\
\text { ratio(\%) }\end{array}$} & \multirow{2}{*}{$\begin{array}{l}\text { Prevalence of active caries* } \\
(\%)\end{array}$} \\
\hline & & $\overline{\mathbf{x}}$ & $S$ & & & \\
\hline \multirow[t]{2}{*}{ Hukou } & Shenzhen & 1.33 & 1.84 & 52.0 & 44.0 & 37.5 \\
\hline & $\begin{array}{l}\text { Non- } \\
\text { Shenzhen }\end{array}$ & 1.30 & 1.80 & 51.0 & 21.4 & 45.0 \\
\hline Total & & 1.31 & 1.81 & 51.2 & 26.9 & 42.2 \\
\hline
\end{tabular}

The training dataset characteristics and the results of univariate analyses were presented in Table 3, 10 variables in the univariate bivariate analysis were incorporated into the multivariate analysis. After the multiple factors binary logistic regression analysis (Table 3), the following variables were predictors of dentist visit experience: Shenzhen hukou 2.133(1.429-3.185),moderate caries1.404(1.022-1.928) and severe caries 2.546(1.461-4.437) $\square$ Angle Class II malocclusion 1.703(1.134-2.556), sometimes or never toothbrushing 2.985(1.491-5.975), Dental floss usage 1.829(1.250-2.677), having had a toothache within the last 12 months1.469(1.086-1.986), high Knowledge attitude level 1.570(1.106-2.229) and moderate Knowledge attitude level 1.534(1.073-2.193). 
Table 3

Logistic regression for having dental visit experience and Socio-demographic factors, dental status, oral health knowledge \& attitude, and health-related behaviors

\begin{tabular}{|c|c|c|c|c|c|c|c|}
\hline \multirow[t]{3}{*}{ Variables } & & \multicolumn{2}{|c|}{ Dentist visit experience } & \multirow{2}{*}{\multicolumn{2}{|c|}{ Univariate analyses }} & \multirow{2}{*}{\multicolumn{2}{|c|}{ Multivariate analyses }} \\
\hline & & \multirow{2}{*}{$\begin{array}{l}\text { Yes } \\
\mathrm{n} \rrbracket \% \bigotimes\end{array}$} & \multirow[t]{2}{*}{ No } & & & & \\
\hline & & & & $\begin{array}{l}P \\
\text { value }\end{array}$ & OR $₫ 95 \% \mathrm{Cl} \mathbb{}$ & $\begin{array}{l}P \\
\text { value }\end{array}$ & OR $₫ 95 \% \mathrm{CI} \rrbracket$ \\
\hline \multirow[t]{2}{*}{ Gender } & male & $347(36.4 \%)$ & 121(12.7\%) & 0.237 & $1.187(0.893-1.578)$ & & \\
\hline & female & $343(36.0 \%)$ & $142(14.9 \%)$ & & 1.00 & & \\
\hline \multirow[t]{2}{*}{ Hukou } & Shenzhen & $190(19.9 \%)$ & $37(3.9 \%)$ & 0.000 & $2.321(1.578-3.413)$ & 0.000 & $\begin{array}{l}2.133(1.429- \\
3.185)\end{array}$ \\
\hline & $\begin{array}{l}\text { Non- } \\
\text { Shenzhen }\end{array}$ & $500(52.5 \%)$ & $226(23.7 \%)$ & \multicolumn{2}{|c|}{ Reference } & & \\
\hline \multirow{2}{*}{$\begin{array}{l}\text { Street } \\
\text { economy }\end{array}$} & good & $462(44.7 \%)$ & 138(14.5\%) & 0.009 & $1.462(1.097-1.947)$ & & \\
\hline & poor & $264(27.7 \%)$ & 125(13.1\%) & \multicolumn{2}{|c|}{ Reference } & & \\
\hline \multirow{2}{*}{$\begin{array}{l}\text { Father's } \\
\text { educational } \\
\text { level }\end{array}$} & $凶 8 y$ & $406(42.6 \%)$ & $140(14.7 \%)$ & 0.118 & $\begin{array}{l}1.256(0.944- \\
1.671)\end{array}$ & & \\
\hline & $\leq 8 y$ & $284(29.8 \%)$ & $123(12.9 \%)$ & & Reference & & \\
\hline \multirow{2}{*}{$\begin{array}{l}\text { Mother's } \\
\text { educational } \\
\text { level }\end{array}$} & $\triangle 8 y$ & $360(37.8 \%)$ & $112(11.8 \%)$ & 0.008 & $\begin{array}{l}1.471(1.104- \\
1.959)\end{array}$ & & \\
\hline & $\leq 8 y$ & $330(34.6 \%)$ & 151(15.8\%) & & Reference & & \\
\hline \multirow[t]{3}{*}{ Caries degree } & severe & $100(10.5 \%)$ & $18(1.9 \%)$ & 0.000 & $2.698(1.575-4.620)$ & 0.001 & $\begin{array}{l}2.546(1.461- \\
4.437)\end{array}$ \\
\hline & moderate & $277(29.1 \%)$ & $93(9.8 \%)$ & 0.018 & $1.446(1.067-1.961)$ & 0.036 & $\begin{array}{l}1.404(1.022- \\
1.928)\end{array}$ \\
\hline & zero & $313(32.8 \%)$ & $152(15.9 \%)$ & \multicolumn{2}{|c|}{ Reference } & & \\
\hline \multirow{2}{*}{$\begin{array}{l}\text { Gingival } \\
\text { bleeding }\end{array}$} & Yes & $519(54.5 \%)$ & 186(19.5\%) & 0.158 & $1.256(0.915-1.725)$ & & \\
\hline & No & $171(17.9 \%)$ & 77(8.1\%) & \multicolumn{2}{|c|}{ Reference } & & \\
\hline \multirow[t]{2}{*}{ Calculus } & Yes & $247(25.9 \%)$ & $109(11.4 \%)$ & 0.108 & $0.788(0.589-1.053)$ & & \\
\hline & No & $443(46.5 \%)$ & $154(16.2 \%)$ & \multicolumn{2}{|c|}{ Reference } & & \\
\hline \multirow[t]{2}{*}{$\begin{array}{l}\text { Angle Class II } \\
\text { malocclusion }\end{array}$} & Yes & $148(15.5 \%)$ & $38(4.0 \%)$ & 0.015 & $1.617(1.096-2.385)$ & 0.010 & $\begin{array}{l}1.703(1.134- \\
2.556)\end{array}$ \\
\hline & No & $542(56.9 \%)$ & $225(23.6 \%)$ & \multicolumn{2}{|c|}{ Reference } & & \\
\hline \multirow{2}{*}{$\begin{array}{l}\text { Angle Class III } \\
\text { malocclusion }\end{array}$} & Yes & $150(15.7 \%)$ & $73(7.7 \%)$ & 0.050 & $0.723(0.522-1.001)$ & & \\
\hline & No & $540(56.7 \%)$ & 190(19.9\%) & \multicolumn{2}{|c|}{ Reference } & & \\
\hline \multirow{2}{*}{$\begin{array}{l}\text { anterior deep } \\
\text { overjet }\end{array}$} & Yes & $433(45.4 \%)$ & 149(15.6\%) & 0.085 & $1.289(0.966-1.720)$ & & \\
\hline & No & $257(27.0 \%)$ & $114(12.0 \%)$ & \multicolumn{2}{|c|}{ Reference } & & \\
\hline \multirow[t]{2}{*}{$\begin{array}{l}\text { Toothbrushing } \\
\text { frequency }\end{array}$} & $\begin{array}{l}\text { Sometimes } \\
\text { or never }\end{array}$ & $18(1.9 \%)$ & $20(2.1 \%)$ & 0.001 & $3.073(1.599-5.906)$ & 0.002 & $\begin{array}{l}2.985(1.491- \\
5.975)\end{array}$ \\
\hline & Daily & $672(70.5 \%)$ & $243(25.5 \%)$ & \multicolumn{2}{|c|}{ Reference } & & \\
\hline
\end{tabular}




\begin{tabular}{|c|c|c|c|c|c|c|c|}
\hline \multirow[t]{2}{*}{$\begin{array}{l}\text { Dental floss } \\
\text { usage }\end{array}$} & Yes & 196(20.6\%) & $43(4.5 \%)$ & 0.000 & $2.030(1.407-2.928)$ & 0.002 & $\begin{array}{l}1.829(1.250- \\
2.677)\end{array}$ \\
\hline & No & $494(51.8 \%)$ & $220(23.1 \%)$ & \multicolumn{4}{|c|}{ Reference } \\
\hline \multirow{3}{*}{$\begin{array}{l}\text { Sugar intake } \\
\text { level }\end{array}$} & high & $148(15.5 \%)$ & $76(8.0 \%)$ & 0.790 & $0.938(0.588-1.498)$ & & \\
\hline & moderate & $459(48.2 \%)$ & $147(15.4 \%)$ & 0.057 & $1.505(0.988-2.291)$ & & \\
\hline & low & $83(8.7 \%)$ & $40(4.2 \%)$ & \multicolumn{4}{|c|}{ Reference } \\
\hline \multirow{2}{*}{$\begin{array}{l}\text { toothache } \\
\text { within the last } \\
12 \text { months }\end{array}$} & Yes & $371(38.9 \%)$ & $114(12.0 \%)$ & 0.004 & $1.520(1.142-2.024)$ & 0.013 & $\begin{array}{l}1.469(1.086- \\
1.986)\end{array}$ \\
\hline & No & $319(33.5 \%)$ & $149(15.6 \%)$ & \multicolumn{4}{|c|}{ Reference } \\
\hline \multirow[t]{3}{*}{$\begin{array}{l}\text { Knowledge- } \\
\text { attitude level }\end{array}$} & high & $234(24.6 \%)$ & $72(7.6 \%)$ & 0.007 & $1.618(1.141-2.293)$ & 0.012 & $\begin{array}{l}1.570(1.106- \\
2.229)\end{array}$ \\
\hline & moderate & $233(24.4 \%)$ & $80(8.4 \%)$ & 0.033 & $1.450(1.031-2.039)$ & 0.019 & $\begin{array}{l}1.534(1.073- \\
2.193)\end{array}$ \\
\hline & low & $223(23.4 \%)$ & $111(11,6 \%)$ & \multicolumn{4}{|c|}{ Reference } \\
\hline \multirow{3}{*}{$\begin{array}{l}\text { Affect the } \\
\text { OHRQoL }\end{array}$} & Yes & $68(7.1 \%)$ & $24(2.5 \%)$ & 0.264 & $1.357(0.794-1.891)$ & & \\
\hline & Slight & $455(47.7 \%)$ & $159(16.7 \%)$ & 0.055 & $1.371(0.994-2.320)$ & & \\
\hline & No & $167(17.5 \%)$ & $80(8.4 \%)$ & \multicolumn{4}{|c|}{ Reference } \\
\hline
\end{tabular}

\section{Discussion}

This study focused on the effects of socio-demographic factors, dental status, oral health literacy, and health-related behaviors on dental visits in early 12-year-old adolescents in Longhua District of Shenzhen. The overall prevalence of dental caries was 51.2\%,which is consistent with the results of epidemiological survey in Guangdong Province in 2019 (57.83\%) [15], and was much higher than the prevalence among 12-year-old children nationwide in China (38.5\%)[16]. As an economically developed area, Longhua District of Shenzhen seems to have more serious dental caries, which will be discussed in our further epidemiological investigation. The overall mean DMFT caries was 1.31 (1.33 and 1.30 in Shenzhen hukou and non-Shenzhen hukou, respectively). The filling rate was $26.9 \%$, and this value was higher in Shenzhen hukou (44.0\%) than non-Shenzhen hukou (21.4\%). We define active caries as DT >0 to describe the number of existing caries】the results showed that the prevalence of active caries in Shenzhen hukou was $37.5 \%$, which was lower than non-Shenzhen hukou(45.0\%). The prevalence of dental caries in Shenzhen hukou (52.0\%) and non-Shenzhen hukou (51.0\%) is almost the same. Under the premise of the same severe dental caries, the filling ratio of Shenzhen hukou and non-Shenzhen hukou is different. After filling treatment, the prevalence of active caries in Shenzhen hukou is lower than that in non-Shenzhen hukou. The results showed that treatment intervention could improve the status of active caries, and the reasons for the difference in filling rate between Shenzhen and non-Shenzhen accounts aroused our interest. Therefore, we further analyzed the dental visit and its influencing factors.

Multivariate binary logistic regression analysis found that,Shenzhen hukou, more serious caries, Angle Class II malocclusion, without daily toothbrushing, Dental floss usage, higher Knowledge-attitude level were predictors of dental visit experience among 12-year-old adolescents. This is the first study on dental visit and related factors in Shenzhen's 12-year-old's registered residence. These findings are important because they can help develop prevention strategies to reduce differences in the use of dental services during a period of changing oral health attitudes.

Shenzhen is one of the fastest growing cities in China, and its per capita GDP has been ranked first level in Chinese cities. The Longhua District has a large area of industrial zone, gathering a large number of migrant workers [17]. In this study, there are significant differences in dental visit between Shenzhen hukou and non-Shenzhen hukou, which reminds that the 
inequity of medical resources has been reflected in the oral diseases of 12-year-old children. In addition to the rapid economic construction, it is also necessary to increase the investment in basic medical care. In particular, it is easier to improve the current situation of dental caries by promoting the oral health service utilization of non-Shenzhen hukou (like community health care).

Our results confirmed that of a previous study which found that need factors were always direct reasons for oral health service utilization [18]. The more serious the caries is, the more likely it is to see a dentist, similar findings have been reported $[18,19]$. In addition, the continuous development of dental caries could further cause toothache, toothache experiences within the last 12 months were associated factors for dental visits, which was reported to be the most common reason for dental visits in most developing counties $[20,21]$. Angle Class II malocclusion was also the reason to promote dental visit. It can be interpreted as Angle Class II malocclusion is handicapping both functionally and socially [22].

Not-daily brushing and flossing habits and good oral health knowledge and attitude can also promote the dental visits. A similar finding has been reported for adults [23]. Without good oral cleaning habits, oral problems are more likely to occur, which increases the demand for dental care, which is consistent with common sense. A previous study found that adolescents who received dental information had a great frequency of visiting a dentist compared to those who did not receive such information [24]. A higher level of oral health knowledge and attitude is believed to favor the acquisition of oral health information and exert a positive influence on visiting a dentist. This information is important, as the use of wellorganized dental services based on preventive care contributes to the maintenance of oral health, which is particularly important in populations with a high risk of oral health problems. It shows that the popularization of oral health care knowledge is very important. Increasing publicity, depth and breadth, cultivating good oral health knowledge and attitude, and promoting good oral health habits are conducive to oral health.

There must be limitations in our research, such as more data collection on family background, especially economic background. In addition, the cross-sectional design does not enable the determination of cause-and-effect relations among the variables. The main outcome of the study (dental visits) was self-reported by the adolescents, which increases the risk of memory bias, it is necessary to improve the design of epidemiological investigation in the future]

\section{Conclusion}

The dental visits of 12-year-old children in Longhua District of Shenzhen is affected by multi-dimensional factors. Shenzhen hukou, good oral hygiene habits and correct oral knowledge and attitude have a higher dental visit rate. people with Angle Class II malocclusion would be more eager to seek dental care. It is suggested that oral health education should be strengthened, good oral hygiene habits should be cultivated, and the needs and utilization of oral health services for nonShenzhen adolescents should be paid attention to, so as to effectively improve the overall oral health level of adolescents.

\section{Abbreviations}

OHRQoL: Oral health-related quality of life;

CSDH: Commission on social determinants of health;

WHO: World Health Organization;

PPS: Probability-proportional-to-size;

BOP: Bleeding on probing;

CPI probe: Community periodontal index probe;

SE: Standard error;

Page $10 / 12$ 
OR: Odds ratio

\section{Declarations}

\section{Ethics approval and consent to participate}

Ethics approval was obtained from Medical Ethics Committee of Longhua People' s Hospital Affiliated to Southern Medical University (Approval No. KY20201104). All adolescents and their statutory guardians were required to sign an informed consent form, the informed consent form contains the survey content about adolescents and their statutory guardians.

\section{Consent for publication}

Not applicable.

\section{Availability of data and materials}

The datasets used and/or analysed during the current study are available from the corresponding author on reasonable request.

\section{Competing interests}

The authors declare that they have no competing interests.

\section{Funding}

This survey was funded by National Natural Science Foundation of China (No. U20A20365 and No. 81901014), Medical Science and Technology Foundation of Guangdong Province, China (Grant No. B2021008) and Research and Development Program of West China Hospital of Stomatology, Sichuan University (No. LCYJ2020-YJ-2). The funders of the study had no role in the design of the study and collection, analysis, and interpretation of data and in writing the manuscript.

\section{Authors' contributions}

HJ, YB: Acquisition of data, analysis and interpretation of data, drafting the article or revising it critically for important intellectual content approved the manuscript. CL, YY, HT: Principal investigator involved in study conception and design, acquisition of data, and provided final approval of the version to be published. $\mathrm{CH}$ : Interpreted the data, revised the manuscript. ZS, PS, XY: Data collection and approved the manuscript. All authors read and approved the final manuscript.

\section{Acknowledgements}

The authors thank the technical assistance provided by the Shenzhen Longhua District Education Bureau, survey team from the West China Hospital of Stomatology, Sichuan University, P. R. China and the People's Hospital of New District Longhua, Shenzhen, China.

\section{References}

1. Petersen P E, Bourgeois D, Ogawa H, Estupinan-Day S, Ndiaye, C. The global burden of oral diseases and risks to oral health. Bulletin of the World Health Organization.2005;83(9):661-9.

2. Broadbent J M, Thomson W M, Poulton R. Trajectory Patterns of Dental Caries Experience in the Permanent Dentition to the Fourth Decade of Life. Journal of Dental Research. 2008; 87(1):69-72.

3. Pitts N, Amaechi B, Niederman R, Acevedo AM, Vianna R, et al. Global oral health inequalities: dental caries task groupresearch agenda. Adv Dent Res, 2011; 23(2):211-220. 
4. Yin W, Yang YM, Chen H, Li X, Wang Z, et al. Oral health status in Sichuan Province: findings from the oral health survey of Sichuan, 2015-2016. International Journal of Oral Science. 2017; 9(1):10-15.

5. Listl S. Family composition and children's dental health behavior: evidence from Germany. Journal of Public Health Dentistry, 2011; 71.

6. Ferreira LL, Brandão GA, Garcia G, Batista MJ, Costa Lda S, et al. Family cohesion associated with oral health, socioeconomic factors and health behavior. Ciência \& Saúde Coletiva. 2013;18(8):2461-73.

7. Horowitz AM, Kleinman DV. Oral health literacy: a pathway to reducing oral health disparities in Maryland. Journal of Public Health Dentistry. 2012; 72 Suppl 1: S32.

8. Sischo L, Broder HL. Oral Health-Related Quality of Life: What, Why, How and Future Implications. Journal of Dental Research. 2011; 90(11):1264.

9. Gilchrist F, Rodd H, Deery C, Marshman Z. Assessment of the quality of measures of child oral health-related quality of life. BMC Oral Health. 2014; 14(1):1-17.

10. Chen X, Ye W, Zhan JY, Wang X, Tai BJ, et al. Periodontal Status of Chinese Adolescents: Findings from the 4th National Oral Health Survey. Chin J Dent Res. 2018;21(3):195-203.

11. Carmo CDS, Ribeiro MRC, Teixeira JXP, Alves CMC, Franco MM, et al. Added Sugar Consumption and Chronic Oral Disease Burden among Adolescents in Brazil. J Dent Res. 2018;97(5):508-514.

12. Wang L, Cheng L, Yuan B, Hong X, Hu T. Association between socio-economic status and dental caries in elderly people in Sichuan Province, China: a cross-sectional study. BMJ Open. 2017;7(9): e016557.

13. World Health Organization (WHO). Oral health surveys: basic methods. 5thed. Geneva: World Health Organization; 2013.

14. Elias-Boneta AR, Ramirez K, Rivas-Tumanyan S, Murillo M, Toro MJ. Prevalence of gingivitis and calculus in 12-year-old Puerto Ricans: a cross-sectional study. BMC Oral Health. 2018;18(1):13.

15. Cheng YH, Liao Y, Chen DY, Wang Y, Wu Y. Prevalence of dental caries and its association with body mass index among school-age children in Shenzhen, China. BMC Oral Health. 2019;19(1):270.

16. Quan JK, Wang XZ, Sun XY, Yuan C, Liu XN, et al. Permanent Teeth Caries Status of 12- to 15-year-olds in China: Findings from the 4th National Oral Health Survey. Chin J Dent Res. 2018;21(3):181-193.

17. Zhou C, Gao Y, Wang S. The Characters and Influencing Mechanism of Spatial-temporal Variations of Migrant Workers in Shenzhen. Scientia Geographica Sinica. 2016.

18. Xu M, Yuan C, Sun X, Cheng M, Xie Y, Si Y. Oral health service utilization patterns among preschool children in Beijing, China. BMC Oral Health. 2018;18(1):31.

19. Qiu RM, Tao Y, Zhou Y, Zhi QH, Lin HC. The relationship between children's oral health-related behaviors and their caregiver's social support. BMC Oral Health. 2016;16(1):86.

20. Machry RV, Tuchtenhagen S, Agostini BA, da Silva Teixeira CR, Piovesan C, Mendes FM, Ardenghi TM. Socioeconomic and psychosocial predictors of dental healthcare use among Brazilian preschool children. BMC Oral Health. 2013; 13:60.

21. Villalobos-Rodelo JJ, Medina-Solís CE, Maupomé G, Lamadrid-Figueroa H, Casanova-Rosado AJ, et al. Dental needs and socioeconomic status associated with utilization of dental services in the presence of dental pain: a case-control study in children. J Orofac Pain. 2010;24(3):279-86.

22. Dann C 4th, Phillips C, Broder HL, Tulloch JF. Self-concept, Class II malocclusion, and early treatment. Angle Orthod. 1995;65(6):411-6.

23. Sistani MM, Yazdani R, Virtanen J, Pakdaman A, Murtomaa H. Oral health literacy and information sources among adults in Tehran, Iran. Community Dent Health. 2013;30(3):178-82.

24. Ekanayake L, Ando Y, Miyazaki H. Patterns and factors affecting dental utilisation among adolescents in Sri Lanka. Int Dent J. 2001;51(5):353-8. 